\title{
Pengaruh Konsep Gamifikasi Terhadap Tingkat Engagement
}

\author{
(Studi Kasus Pelatihan Karyawan the Park Lane Jakarta)
}

\author{
Aditya Pratomo \\ Universitas Bina Nusantara \\ pratomo_aditya@binus.ac.id
}

\begin{abstract}
The survey results conducted Director of Learning, engagement level for leaders The Park Lane Jakarta is quite a low of $23 \%$ when engagement leaders low then it is likely his engagement will be the same. Then with the implementation of the concept of gamification is expected to enhance the engagement of employees towards learning. Type of this research is descriptive research with survey method. To the object of research is the hotel The Park Lane Jakarta. The independent variable is the influence of the concept of the dependent variable and the gamification is the engagement of employees. For a data source used is the primary and secondary data of a population of 269 and value precision of $10 \%$. Based on the results of research that the concept of gamification gives a significant impact on employee engagement, there is $38.4 \%$ against employee engagement. As well as according to hypothesis testing is evidenced by the receipt of the Ha and turned it on test of the Ho hypothesis.
\end{abstract}

\section{Keywords-The Concept of Gamifikasi, Engagement}

Abstrak-Hasil survey yang dilakukan Director of Learning, leaders engagement level untuk The Park Lane Jakarta cukup rendah sebesar 23\% apabila engagement leaders rendah maka kemungkinan engagement bawahannya akan sama. Maka dengan diimplementasikannya konsep gamification diharapkan dapat meningkatkan engagement karyawan terhadap learning. Jenis penelitian ini adalah penelitian deskriptif dengan metode survei. Untuk objek penelitian adalh hotel The Park Lane Jakarta. Variabel independen adalah pengaruh konsep gamification dan variabel dependen adalah engagement karyawan. Untuk sumber data yang digunakan adalah data primer dan sekunder dengan populasi sebanyak 269 dan nilai presisi sebesar 10\%, sampel yang digunakan adalah 73 karyawan untuk mewakili populasi karyawan The Park Lane Jakarta. Berdasarkan hasil penelitian bahwa konsep gamification memberikan dampak yang signifikan terhadap employee engagement berdasarkan hasil pengolahan data yang dilakukan oleh peneliti, ditemukan adanya pengaruh sebesar $38,4 \%$ terhadap employee engagement. Serta menurut pengujian hipotesis dibuktikan dengan diterimanya $\mathrm{Ha}$ dan ditolaknya $\mathrm{Ho}$ pada uji hipotesis.

\section{Kata kunci-Konsep Gamifikasi, Engagement}

\section{PENDAHULUAN}

Pertumbuhan bisnis pariwisata setiap tahunnya semakin meningkat, bahkan Sektor pariwisata Indonesia telah mencatat pertumbuhan signifikan 25,68 persen sepanjang pada tahun 2017, melampaui kawasan Asia Pasifik dan pasar negara berkembang lainnya. Hal ini tentu juga membuat pertumbuhan bisnis perhotelan juga semakin meningkat, sehingga menciptakan kompetisi yang semakin ketat.

Pertambahan hotel yang cukup signifikan, menjadikan setiap hotel berkompetisi dan menjaga perusahaan mereka agar tidak kalah saing dengan hotel-hotel yang baru berkembang lainnya. Untuk memenangkan persaingan maka setiap hotel harus memberikan pelayanan yang maksimal dan berusaha sekuat mungkin untuk memuaskan pelanggan. Kualitas pelayanan yang baik tentu akan membuat hotel mampu bersaing ditengah kompetisi yang semakin ketat. Maka dari itu untuk menciptakan kualitas pelayanan yang unggul, maka kinerja karyawanpun juga harus semakin meningkat.

Kualitas pelayanan yang baik didapatkan salah satunya melalui training. Setiap perusahaan memiliki kost tersendiri untuk setiap training yang diikuti oleh karyawan mereka. Bahkan perusahaan membayar untuk training, baik itu yang telah diprogramkan maupun yang tidak. Perusahaan dapat menentukan nilai dari training dengan mengambil keuntungan yang diberikan oleh training tersebut. Sebuah departemen training dan development menyaring pengetahuan yang sesuai dengan kebutuhan para karyawan untuk tetap menunjang kemampuan meraka. Karena dengan training karyawan dapat dilatih dalam melakukan pekerjaan, sehingga dengan melakukan satu kali percobaan tanpa 
mengulang akan lebih menghemat biaya dari pada mengulangnya kembali.

Training merupakan salah satu bentuk dari bentuk learning yang diterapkan dalam perusahaan, menurut French, Rayne, Rees dan Rumbles (2015:82) "learning is a relatively permanent change in behavior that occurs as a result of experience". Seiring perubahan zaman, pelatihan yang bersifat kaku, banyak teori serta presentasi membuat proses pelatihan menjadi membosakan dan menyebabkan kurangnya motivasi karyawan untuk mengikuti pelatihan. Menurut Mangkuprawira (2014:134) bahwa "pelatihan merupakan sebuah proses mengajarkan pengetahuan dan keahlian tertentu, serta sikap agar karyawan semakin terampil dan mampu melaksanakan tanggung jawabnya dengan baik, sesuai dengan standar."

Perkembangan training yang diterapkan oleh hampir semua perusahaan, berubah setiap tahunnya. Semua mengikuti perkembangan zaman yang ada. Pada tahun 1990 metode training yang masih digunakan adalah INTRO, yaitu Interest, Needs, Title, Range, Objective proses pelatihan tersebut masih memulai training dengan cara memunculkan minat para peserta menggunakan cerita-cerita maupun trik menarik, kemudian menjelaskan alasan mengapa training ini dibutuhkan dalam perusahaan.

Pada tahun 2000 munculah televisi yang mempengaruhi training tepatnya pada bagian metode penyampaiannya yaitu, menjadi 10 menit traineer berbicara menyampaikan materi dan 3 menit materi berupa visual dikarenakan televisi bersifat memberikan informasi secara cepat, menarik perhatian dengan durasi yang singkat dengan tampilan visual yang membuat informasi mudah dingat. Menurut Biagi (2015: 152) mengatakan "Television technology, by adding pictures to the sounds of radio, truly transformed Americans living \& learning patterns"

Beranjak pada tahun 2010 social media muncul dan penyampaian informasi menjadi lebih cepat dan luas serta adanya terjadinya convergence. Menurut Biagi (2015:179) convergence is the melding of the communications, computer \& electronics industry. Hal ini membuat orang lebih banyak menghabiskan waktu dengan smartphone, tablet, maupun laptop.

Sebagian besar orang-orang menggunakan smartphone hampir setiap saat untuk keperluan seperti browsing, social media, games, etc. dan berdasarkan data yang ada, sekitar $83 \%$ orangorang menggunakannya untuk bermain games hal ini membuktikan bahwa hampir semua orang mengenal games. Pada umumnya game hanya dianggap untuk permainan anak-anak dan remaja, Namun Umur bukanlah hal yang menjadi penghalang untuk bermain games.

Berkembangnya waktu, kita mengenal istilah gamification. Kata Gamification mulai sering digunakan pada tahun 2010, namun belum banyak pembahasan mengenai hal tersebut dikarenakan hal-hal yang berkaitan dengan games dan video game tidak terlalu diperhatikan. Gamification sendiri adalah proses pengaplikasian desain dan konsep game pada proses pembelajaran atau pelatihan dengan tujuan agar lebih menarik serta menghibur untuk peserta sehingga dapat meningkatkan (www.trainingindustry.com)

Konsep Gamification dapat diimplementasikan dalam banyak sektor seperti Marketing, Training dan Education. Menurut Hamari dan Santhanam dalam Wagner (2017), "Research has found that the use of gamification significantly increase user engagement of an online service and learning performance in education". The Park Lane Jakarta merupakan hotel pertama yang mengadaptasi konsep gamification yang diimplementasikan pada Learning. Seluruh pelatihan yang diadakan dikombinasikan dengan konsep gamification seperti Suggestive Selling Skills, I AM TPLJ, Proffesionalism 2020, dan Mellenial Sales \& Marketing pelatihan tersebut menggunakan konsep gamification salah satu bentuknya adalah pelatihan I AM TPLJ yang merupakan pelatihan yang memberikan pembekalan kepada karyawannya mengenai nilai-nilai The Park Lane Jakarta yang baru diadaptasi, Dalam pelatihan ini setiap karyawan perkenalkan dengan nilai-nilai baru yaitu Staycation, Value For Money, Resort Like, dan Playful di bagi menjadi 4 kelompok dan masing-masing kelompok menjelaskan masing-masing nilai tersebut dengan menggunakan menggunakan kertas karton sebagai media untuk menempelkan planning hasil karya mereka untuk mendeskripsikan bagaimana kedepannya The Park Lane Jakarta mengaplikasikan nilainilai tersebut.

Setelah masing-masing menyelesaikannya, maka perwakilan dari masing-masing kelompok akan maju dan menjelaskan hasil karya mereka. Dari hasil penjelasan masingmasing kelompok mereka akan mendapatkan penilaian dari Traineer dengan sistem poin dengan 5 kriteria penilaian (Punctuality,Pretest, English, Active, Post-test), penilaian dilakukan terhadap kelompok dan masingmasing individu tersebut. Skor tersebut akan 
diakumulasikan kemudian di masukkan kedalam leaderboard, perolehan skor tertinggi akan memperoleh Medali dan menjadi bahan pertimbangan untuk promosi. Konsep Gamification memiliki beberapa elemen yaitu, Leaderboard, Badges atau Archievement (Jeffrey dan Elisabeth, 2016) pelatihan I AM TPLJ mengangkat beberapa elemen dari konsep gamification yaitu Leaderboard, Badges atau Archievement.

Dari pengaplikasian konsep gamification tersebut barulah muncul hasil engagement karyawan selama agustus-desember, berikut adalah data-data mengenai Engagement Karyawan The Park Lane Jakarta: Berdasarkan hasil survey yang dilakukan oleh Director of Learning yaitu leaders engagement level untuk The Park Lane Jakarta adalah 23\% berdasarkan perhitungan dari Product Knowledge Week (47\%), Departemental Trainer Monthly Meeting (17\%), Email to Department Heads' individual addresses (0\%), Smile Campaign (0\%), English Club (60\%). Hasil survey menunjukkan bahwa level engagement of leaders The Park Lane Jakarta rendah yaitu 23\% apabila engagement leaders rendah maka begitu pula dengan engagement bawahannya, Menurut Saks dalam Nada Al Mehrzi dan Sanjay Kumar Singh (2016), "Engagement reflect a two-way exchange between workers and managers" yaitu apabila seorang leaders tidak engaged maka bawahannya juga tidak engaged. Sehingga dengan diimplementasikannya konsep gamification diharapkan dapat meningkatkan engagement karyawan terhadap learning.

Keterangan dan data-data hasil observasi peneliti di atas merupakan gambaran awal dari tulisan ini. Adapun tujuan dari penelitian ini adalah untuk mengetahui bagaimana pengaplikasian konsep gamification pada learning di hotel The Park Lane Jakarta, kemudian untuk mengetahui bagaimana tingkat engagement karyawan The Park Lane Jakarta, serta untuk mengetahui apakah pengaplikasian konsep gamification pada learning memberikan pengaruh signifikan terhadap tingkat engagement karyawan The Park Lane Jakarta.

\section{KAJIAN PUSTAKA}

\section{A. Defini Pelatihan}

Menurut Jan Bella dalam Graha (2012) dalam jurnal nasional yang berjudul "Pengaruh Pelatihan dan Komunikasi Terhadap Kinerja Karyawan Call Center di Bandung" menjelaskan definisi pelatihan sebagai berikut: "Pendidikan dan Latihan sama dengan pengembangan yaitu merupakan proses peningkatan keterampilan kerja baik teknis maupun manajerial. Pendidikan berorientasi pada teori, dilakukan dalam kelas, berlangsung lama, dan biasanya menjawab why. Latihan berorientasi pada praktek, dilakukan di lapangan, berlangsung singkat biasanya menjawab how."

Menurut Mangkuprawira dalam buku Manajemen Sumber Daya Manusia Satrategik (2014:133) "Pelatihan bagi karyawan merupakan sebuah proses mengajarkan pengetahuan dan keahlian tertentu serta sikap agar karyawan semakin terampil dan mampu melaksanakan tanggung jawabnya dengan baik sesuai dengan standar." Maka berdasarkan pendapat-pendapat para ahli, dapat disimpulkan bahwa pelatihan adalah merupakan proses peningkatan pengetahuan serta keterampilan kerja karyawan sehingga adanya perubahan kearah lebih baik.

Pelatihan-pelatihan tersebut menurut Sikula dalam Priansa (2014:176-178), bertujuan untuk meningkatkan produktivitas, memperbaiki kualitas, terciptanya perencanaan kerja pegawai, meningkatkan moril kerja pegawai untuk lebih bertanggung jawab terhadap tugasnya, memberikan kesempatan bagi pegawai untuk lebih dapat mengembangkan diri, meningkatkan keselamatan dan kesehatan kerja, meningkatkan kreatifitas pegawai serta memberikan kesempatan bagi pegawai untuk meningkatkan pengetahuan dan kemampuan yang dimiliki pegawai termasuk meningkatkan perkembangan pribadinya.

\section{B. Gamification}

Palmer dalam jurnal Conaway (2014) yang berjudul "Gamification and service marketing" menjelaskan definisi gamification sebagai berikut: "Gamification is taking the essence of games-fun, play, transparency, design, challenge-and applying it to real-world objectives rather than pure entertainment"

Pendapat lain dikemukan oleh Deterding dalam jurnal Han (2015) yang berjudul "Gamified Pedagogy: From Gaming Theory to Creating a Self-Motivated Learning Environment in Studio Art" mendefinisikan gamification sebagai berikut: "Gamification is using game design elements In non-contexts to motivate and increase user activity and retention". Maka berdasarkan pendapatpendapat para ahli, dapat disimpulkan bahwa Gamification merupakan suatu proses pengaplikasian unsur-unsur yang ada dalam game pada hal-hal non-konteks dengan tujuan memotivasi dan meningkatkan keterlibatan penggunanya.

Menurut jurnal Jeffrey dan Elisabeth (2016) dalam jurnal yang berjudul "A framework for 
understanding game-based teaching and learning" menjelaskan elemen-elemen dari gamification: "One use of gamification is to turn learning into game by adopting games elements and structures. These game elements can include everything from leaderboards, badges or "archievement" all the way to fully realized game narrative".

Lebih jauh, Karl M.Kapp, Lucas Blair, dan Rich Mesch. (2014: 137-149) dalam buku yang berjudul "The Gamification of Learning and Instruction Field Book : Ideas Into Practice". Elemen-elemen dari gamification adalah sebagai berikut: 1). Feedback. We give feedback to players to create a feedback loop. In a feedback loop the system gives players information about their performance or game state, and with this information the players can change their behavior. When creating feedback, we must account for the timing, tone, and delivery method. a). Timing Feedback; b). Tone of Feedback; c). Feedback Delivery. 2). Constructs. Construct are used to make the players' experience more interesting, give them better information, or enhance training effectiveness by accentuating certain aspects of an interaction. Construct can also be used to limit or empower the players. When creating construct it is important that it have some kind of purpose. Constructs can take many forms such as game mechanics, allegory, laws and rules. a). Game Mechanics; b). Allegory; c). Laws and rules. 3). Challenge. Challenge is a good thing in games, gamification and simulations. Design challenge to scale with player experience to keep them engaged and motivated. Keeping players teetering on fine line between boredom and stress is what makes players fall into flow state. If you go too far in making challenge the player will be overwhelmed, and if you do not do enough they will lose interest; 4). Story. It creates a setting similar to where the player would use skills or knowledge they acquire. One benefit is that it creates a setting similar to where players would use skills or knowledge they acquire. Having story also helps players create a mental mode of an entire process and in some cases stay motivated because they wanted to know what happened next; 5). Exaggerated Story. Is used in games to put players in a situation when typical experience will not keep them engaged or training for an extreme event will prepare them for all other possibilities.

Ada banyak manfaat dan nilai-nilai yang dihasilkan dari Gamification, menurut Sakamoto, M., Nakajima, T., Alexandrova, T., (2012) dalam jurnal yang berjudul "Valuebased design for gamifying daily activities" menyebutkan nilai-nilai gamification: 1).
Informative Value; 2). Empathetic Value; 3). Persuasive Value; 4). Economic Value; 5). Ideological Value

\section{Employee Engagement}

Dalam sebuah buku yang ditulis oleh Shuck dan Wollard dalam Ray French (2015:132) yang berjudul "Organizational Behaviour" mendefinisikan employee engagement sebagai berikut: "Employee engagement is an individual employee's cognitive, emotional and behavioral state directed toward desired organizational outcomes". Pendapat lain dikemukan oleh Khan's dalam Ling Suan Choo, Norslah Mat dan Mohammed Al-Omari (2013) bahwa "Employee engagement is the harnessing of organization members' selves to their work roles; in engagement, people employ and express themselves physically, cognitively, and emotionally during role performances". Sedangkan menurut Akila Narayanan (2014) dalam buku Gamification for Employee Engagement, "Employee engagement can be defined as the degree to which an employee bonded towards his organization or job".

Ada beberapa faktor yang dapat mempengaruhi Employee Engagement, Akila Narayanan (2014) dalam buku Gamification for Employee Engagement, menjelaskan faktorfaktor yang mempengaruhi Employee Engagement sebagai berikut: 1). Satisfaction. A satisfied employee need not be an engaged employee, but an engaged employee almost always satisfied employee. At the outset, job satisfaction indicate degree to which an employee is content with their job, whereas engagement bespeaks the degree to which an employee goes beyond the call of duty. 75-80\% employee can be satisfied if they are assured of ; job security, financial stability, compensation, benefits, flexibility at the workplace. While satisfaction can't directly contribute to engagement, it certainly disturb the engagement level if not taken care of; 2). Motivation. A satisfied employee need not be motivated employee and motivated employee not be an engaged employee, whereas an engaged employee is almost always a satisfiedcum-motivated employee. Motivation refers to psychological drive that reinforced one's action toward accomplishing task or goals. It clearly indicates why an employee behaves in a certain fashion. There are two categories of motivation: a). Extrinsic Motivation; b). Intrinsic Motivation; 3). Advancement. Refers to the growth in one's career in term of designation or position, usually in relation to their good performance. This can also involve advancement in term of gaining knowledge, skills, and maturity to move to the next level or undertake challenging assignments. 
Advancement again can be intrinsic in the manner which an employee feels that they have come a long way being part of the continous journey of learning; 4). Recognition. Recognition commonly associated with rewards given as a token of appreciation from accomplishing excellence. It symbolizes acknowledgement of one's good work. From tangibles to virtual awards, recognition can reassure an employee of their value to organization. Recognition need not always translate to something materialistic, what is of utmost importance with respect to recognition is timiness and genuineness; 5). Trust. An employee needs to develop a sense of trust in the organization's purpose of existence and directions from the executive leadership team. Much of disengagement surface when leaders fail to communicate a clear vision. The highest point of trust is accomplished when an employee is able expose their vulnerabilities to the supervisor, seek help, and gain wisdom. When things don't work the way they are planned, supervisor should lend the adequate support rather than blaming it squarely on then subordinates. A simple rule to remember is, trust is mutual.

\section{Hipotesis}

Hipotesis menurut Siregar (2013:38) adalah jawaban atau dugaan sementara yang harus diuji kebenarannya. Didalam penelitian ini, dirumuskan hipotesis sebagai dasar dari dugaan sementara terhadap variabel-variabel yang dirancang sebagai berikut:

H0: Konsep Gamification (X) tidak berpengaruh signifikan terhadap tingkat Employee Engagement (Y) The Park Lane Jakarta.

Ha: Konsep Gamification (X) berpengaruh signifikan terhadap tingkat Employee Engagement (Y) The Park Lane Jakarta.

\section{Metode PENELITIAN}

Penelitian sebagai sebuah konsep pemeriksaan yang teliti, penyelidikan; kegiatan pengumpulan, pengolahan, analisis, dan penyajian data yang dilakukan secara sistematis dan objektif untuk memecahkan suatu persoalan atau menguji suatu hipotesis untuk mengembangkan prinsip-prinsip umum”, maka dari itu penelitian "Pengaruh Konsep Gamifikasi Terhadap Tingkat Engagement Karyawan The Park Lane Jakarta" ini mengunakan metode penelitian kuantitatif. Penelitian kualitatif merupakan penilitian positivis (positivist) yang menekankan pada pengujian teori-teori melalui pengukuran variabel-variabel penelitian dengan angka dan melakukan analisis data dengan statistika.". (Sugiarto 2015:38).

Dalam penelitian ini, jenis penelitian yang digunakan adalah penelitian deskriptif, dimana penelitian deskriptif merupakan sebuah penelitian yang memaparkan suatu karakteristik atau ciri tertentu dari sebuah fenomena permasalahan yang terjadi.". (Sugiarto 2015:42). Adapun metode penelitian yang digunakan dalam penelitian ini adalah metode survei. Metode survey yang digunakan oleh peneliti dalam penelitian ini untuk mengumpulkan data pengaruh konsep gamification terhadap tingkat engagement karyawan The Park Lane Jakarta adalah teknik pengumpulan data, wawancara dan kuesioner.

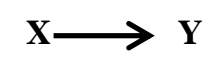

$$
\begin{aligned}
& \mathrm{X}=\text { Konsep Gamification } \\
& \mathrm{Y}=\text { Tingkat Engagement } \text { Karyawan }
\end{aligned}
$$

Secara rentang waktunya, penulis menggunakan data Cross Section. Data Cross Section adalah data yang dikumpulkan pada waktu dan tempat tertentu saja (Sugiarto., 2015:141). Unit analisis adalah satuan yang menunjuk pada subjek penelitian (Arikunto, 2013: 99), yaitu individu yang merupakan karyawan The Park Lane Jakarta.

Penelitian ini dilakukan pada hotel The Park Lane Jakarta yang beralamat di Jl. Casablanca Kav. 18, Menteng Dalam, RT.4/RW.12, Menteng Dalam, Tebet, Kota Jakarta Selatan, Daerah Khusus Ibukota Jakarta 12870, Indonesia. Adapun objek penelitian dari penelitian ini adalah pengaplikasian konsep gamification, pengaruh konsep gamification kepada engagement karyawan, pengaruh konsep gamification terhadap engagement karyawan The Park Lane Jakarta.

Penelitian ini memiliki dua variabel yaitu variabel independen (variabel bebas) dan variabel dependen (variabel terikat). Dalam penelitian ini yang menjadi variabel independen adalah pengaruh konsep gamification dan yang menjadi variabel dependen adalah engagement karyawan. Untuk sumber data yang digunakan adalah data primer dan sekunder. Adapun teknik pengumpulan data dalam penelitian ini adalah dengan menggunakan: 1). Survei; 2). Wawancara; 3). Kuesioner. Pada sebuah kuesioner dibutuhkan skala pengukuran untuk menilai secara numerik indikator-indikator dari tiap variabel atau konsep yang diukur. Pada penelitian ini skala yang akan digunakan untuk mengukur pertanyaan dan pernyataan pada kuesioner adalah skala Likert. dengan lima angka 
penilaian, yaitu: (1) sangat tidak setuju, (2) tidak setuju, (3) tidak pasti atau netral, (4) setuju, (5) sangat setuju.

Populasi dalam penelitian ini adalah karyawan The Park Lane Jakarta yaitu 269 karyawan. Sedangkan untuk menentukan sampel penulis menggunakan rumus Slovin yang memilki fungsi sebagai berikut :

$$
n=\frac{N}{N(d)^{2}+1}
$$

Keterangan:

n : Sampel;

N: Populasi;

d : Nilai presisi

Dengan jumlah populasi sebanyak 269 dan nilai presisi sebesar $10 \%$, sampel yang yang diperoleh oleh penulis adalah 73 karyawan untuk mewakili populasi karyawan The Park Lane Jakarta. Pengambilan sampling peneliti menggunakan probability sampling. Menurut Malhotra, Naresh K (dalam Sugiarto 2015:178), "Probability Sampling adalah prosedur pengambila sampel dengan kondisi setiap elemen populasi memiliki peluang yang tetap untuk terpilih sebagai sampel."

Uji hipotesis dapat dilakukan dengan melakukan uji signifikansi korelasi Product Moment. Hipotesis yang telah ditentukan sebelumnya dalam penelitian ini adalah sebagai berikut:

$\mathrm{H}_{0}$ : Konsep Gamification (X) tidak berpengaruh signifikan terhadap tingkat Employee Engagement (Y) The Park Lane Jakarta.

$\mathrm{H}_{1}$ : Konsep Gamification (X) berpengaruh signifikan terhadap tingkat Employee Engagement (Y) The Park Lane Jakarta.

Ketentuan dalam pembuktian hipotesis dengan menggunakan uji signifikansi korelasi Product Moment yaitu:

1. $\mathrm{H}_{0}$ diterima dan $\mathrm{H}_{1}$ ditolak, apabila $\mathrm{r}$ hitung lebih kecil dari $\mathrm{r}$ tabel ( $\mathrm{r}$ hitung $<$ r tabel)

2. $\mathrm{H}_{1}$ diterima dan $\mathrm{H}_{0}$ ditolak, apabila $\mathrm{r}$ hitung lebih besar dari $\mathrm{r}$ tabel ( $\mathrm{r}$ hitung $>\mathrm{r}$ tabel)

\section{Hasil PENELITIAN DAN PEMBahasan}

\section{A. Gamification di The Park Lane Jakarta}

Gamification adalah pengimplementasian prinsip-prinsip permainan dalam lingkungan non-permainan, sehingga gamification dapat diterapkan di marketing dan pembelajaran. Di The Park Lane Jakarta, konsep gamification diaplikasikan melalui Learning yaitu dengan sistem Learning Score yang memiliki syaratsyarat yang harus di penuhi, yaitu skor untuk masing-masing karyawan harus 1.300 per orang dalam setiap kuarter, apabila karyawan tidak mencapai kriteria minimum skor maka akan dikenakan hukuman berupa Warning. Untuk mencapai skor tersebut ada beberapa cara yang dapat di tempuh yaitu; 1). Mengikuti pelatihan di kelas atau department; 2). Mengikuti pelatihan di website; 3). Mengikuti kuis Product Knowledge; 4). Mengerjakan tugas yang diberikan baik itu kelompok maupun individu.

Setiap kegiatan tersebut memiliki skor yang berbeda-beda disesuaikan dengan bobot tugasnya. Pelatihan yang diadakan di kelas ataupun departement memiliki nilai tersendiri tiap jamnya yaitu 100 point. Untuk pelatihan yang diadakan di Website, karyawan akan mendapatkan 100 point apabila telah menyimak video pelatihan dan mengikuti test yang ada dengan ketentuan jika menjawab semua pertanyaan dengan tepat. Seperti kuis product knowledge yang diadakan setiap hari kamis, peserta diberikan 10 pertanyaan melalui situs The Park Lane dengan bobot nilai 10 point tiap pertanyaannya. Penilaian dilakukan oleh Director of Learning dan hasilnya akan masuk ke skor karyawan. Tugas-tugas yang diberikan juga ada perolehan skor sebesar 150 baik itu kelompok maupun individu.

Perbandingan antara responden perempuan dengan laki-laki dimana didapati jumlah responden laki-laki sebanyak 40 orang $(53.8 \%)$ sementara responden wanita hanya 33 orang $(45.2 \%)$, dimana responden didominasi oleh responden dengan usia $>25$ tahun $(86,3 \%)$, lalu diikuti oleh responden dengan usia 20-25 tahun $(6,8 \%)$, kemudian responden dengan usia $<20$ tahun $(2,75 \%)$.

B. Uji Validitas Konsep Gamification (X) dan Employee Engagement (Y)

Pada penelitian ini pengujian validitas sampel yang digunakan sebanyak 73 responden, pertama dengan menggunakan bantuan program IBM Statistics SPSS versi 24 terhadap variabel Konsep Gamification (X) melalui 10 pertanyaan. Dikatakan valid apabila $r_{\text {hitung }} \geq r_{\text {tabel. }}$. Jika sebaliknya maka dikatakan tidak valid, berikut hasil yang diperoleh bahwa hasil dari setiap item pertanyaan memiliki $r_{\text {hitung }}$ yang besar dari $r_{\text {tabel }}$ yang ditentukan yaitu 0,23 Serta signifikasi pada taraf 0.1 dengan uji 2 sisi lebih kecil dari 0.1. Maka dari itu, dapat disimpulkan bahwa validitas keseluruhan item pertanyaan pada variabel Konsep Gamification (X) adalah baik. 
Untuk pengujian validitas variabel Motivasi Kerja (Y) sampel yang digunakan sebanyak 73 responden pertama dengan menggunakan bantuan program IBM Statistics SPSS versi 24 melalui 10 pertanyaan. Dikatakan valid apabila $r_{\text {hitung }} \geq r_{\text {tabel. }}$ Jika sebaliknya maka dikatakan tidak valid. Hasil dari setiap item pertanyaan memiliki $r_{\text {hitung }}$ yang lebih besar dari $r_{\text {tabel }}$ yang ditentukan yaitu 0.23 . Serta signifikasi pada taraf 0.1 dengan uji 2 sisi lebih kecil dari 0.1 . Maka dari itu, dapat disimpulkan bahwa validitas keseluruhan item pertanyaan pada variabel Employee Engagement (Y) adalah baik.

C. Uji Reliabilitas Konsep Gamification (X) dan Employee Engagement (Y)

Setelah instrumen telah dinyatakan valid maka instrumen tersebut akan diuji reliabilitasnya. Dalam pengujian reliabilitas sampel yang digunakan sebanyak 73 responden pertama dengan menggunakan bantuan program IBM Statistics SPPS versi 24 terhadap variabel konsep Gamification (X) melalui 10 pertanyaan. Hasil dari pengujian akan ditentukan dengan ketentuan sebagai berikut: 1). Reliabilitas < 0,6 adalah buruk; 2). Reliabilitas 0,7 dapat diterima; 3). Reliabilitas $>0,8$ adalah baik. Hasil uji reliabilitas untuk variabel Pelatihan (X) adalah sebesar 0,953, dimana $\mathrm{r}_{10}>0,7$ sehingga alat ukur (pernyataan) yang digunakan adalah baik, serta dikategorikan reliabel dan konsisten.

Hasil uji reliabilitas menggunakan metode Alpha Cronbach dengan bantuan software IBM SPSS (Version 24) untuk variabel Employee Engagement (Y) yang dilakukan terhadap 73 responden pertama terhadap 10 pertanyaan. Hasil uji reliabilitas untuk variabel Motivasi Karyawan (Y) adalah sebesar 0,938 , dimana $\mathbf{r}_{10}$ $>0,7$ sehingga alat ukur (pernyataan) yang digunakan adalah baik, serta dikategorikan reliabel dan konsisten.

D. Analisis Deskriptif Konsep Gamification (X) dan Employee Engagement (Y)

Analisis Deskriptif akan dilakukan berdasarkan masing-masing variabel serta indikator-indikator dalam setiap dimensi yang digunakan, yaitu variabel Konsep Gamification (X) dengan teori dari Karl M.Kapp, Et La. (2014), dan variabel Employee Engagement (Y) dengan teori dari Akila Narayanan (2014). Kedua variabel tersebut telah terbagi menjadi 20 indikator yang telah disusun dalam kuesioner.

Kuesioner penelitian disebarkan kepada 73 responden yang merupakan karyawan yang bekerja di The Park Lane Jakarta. Nilai minimum untuk pernyataan $4,5,6$, dan 7 adalah 1 (Sangat Tidak Setuju). Nilai minimum untuk pernyataan $1,2,3,8,9$, dan 10 adalah 2 (Tidak Setuju). Nilai maksimum untuk seluruh pertanyaan adalah 5 (Sangat Setuju). Warna hijau menunjukkan pernyataan dengan nilai mean terendah, sedangkan warna biru menunjukkan pernyataan dengan nilai mean tertinggi.

Berdasarkan hasil analisis deskriptif dapat diketahui bahwa pernyataan dengan rata-rata nilai mean terendah adalah pernyataan 4 yaitu "Hukuman yang diterapkan membuat saya termotivasi." dengan nilai mean 3,33. Dapat dilihat angka ini masih berada di antara 3 (Netral) dan 4 (Setuju), meskipun nilai mean pernyataan ini adalah yang terendah, namun mayoritas karyawan bersikap netral terhadap pernyataan "Hukuman yang diterapkan membuat saya termotivas". Bentuk dari hukuman yang diterapkan berupa warning dari Human Resources Department. Sedangkan mean dengan nilai tertinggi yaitu 3,99. pada pernyataan 2 yaitu "Saya memahami semua persyaratan untuk mendapatkan learning score". Angka tersebut masih berada di antara angka 3 (Netral) dan 4 (Setuju), sehingga dapat disimpulkan bahwa karyawan setuju bahwa mereka memahami seluruh persyaratan untuk mendapatkan learning score. Pada bagian standar deviasi, menunjukkan bahwa jika nilai deviasi semakin tinggi maka seluruh responden memberikan tanggapan yang beragam sedangkan jika nilai deviasi rendan maka responden menanggapi pernyataan dengan konsisten. Pada tabel diatas dapat dilihat bahwa nilai standar deviasi tertinggi terdapat pada pernyataan nomor 5, sedangkan nilai standar deviasi terendah terdapat pada pernyataan nomor 1 .

Berdasarkan olah data dari kuesioner penelitian yang disebarkan kepada 73 responden yang merupakan karyawan karyawan The Park Lane Jakarta menunjukan bahwa nilai minimum untuk pernyataan 15 adalah 1 (Sangat Tidak Setuju). Nilai minimum untuk pernyataan 11, 12, 13, 17, 19, dan 20 adalah 2 (Tidak Setuju). Nilai Minimum untuk pernyataan 14, 16, dan 18 adalah 3 (Netral). Sedangkan nilai maksimum untuk seluruh pernyataan adalah 5 (Sangat Setuju). Warna Hijau menunjukkan pernyataan dengan nilai mean terendah, sedangkan warna biru menunjukkan pernyataan dengan nilai mean tertinggi.

Selain itu juga dapat diketahui bahwa hasil jawaban responden pada variabel Employee Engagement (Y) secara rata-rata (mean) dengan nilai terendah yaitu 3.68 pada pernyataan 17 yaitu "Ada tanggapan dari 
perusahaan untuk setiap aspirasi yang saya utarakan". Nilai angka tersebut berada di antara 3 (Netral) dan 4 (Setuju). Dari nilai tersebut dapat disimpulkan bahwa mayoritas karyawan setuju aspirasi yang mereka utarakan mendapat tanggapan dari perusahaan.

Selanjutnya, variabel Employee Engagement $(\mathrm{Y})$ dengan nilai rata-rata tertinggi adalah pernyataan 13 yaitu "Saya selalu melakukan yang terbaik untuk meningkatkan kemampuan dalam pekerjaan". Pernyataan ini memiliki nilai mean tertinggi yaitu 4,16 dimana nilai ini masih berada di antara 4 (Setuju) dan 5 (Sangat Setuju). Dapat disimpulkan bahwa mayoritas karyawan The Park Lane Jakarta selalu memberikan yang terbaik untuk meningkatkan kemampuan mereka dalam bekerja. Pada bagian standar deviasi, menunjukkan bahwa jika nilai deviasi semakin tinggi maka seluruh responden memberikan tanggapan yang beragam sedangkan jika nilai deviasi rendah maka responden menanggapi pernyataan dengan konsisten. Pada tabel diatas dapat dilihat bahwa nilai standar deviasi tertinggi terdapat pada pernyataan nomor 15 , sedangkan nilain standar deviasi terendah terdapat pada pernyataan nomor 18 .

Dalam uji korelasi, nilai $\mathrm{R}$ menunjukkan hubungan antara Konsep gamification terhadap tingkat Employee Engagement yaitu sebesar 0,606. Siregar (2016:261) menjelaskan bahwa kriteria keputusan untuk pengujian korelasi atau hubungan dapat dilakukan berdasarkan nilai probabilitas yaitu jika probabilitas (Sig) < a, maka dapat dinyatakan terdapat hubungan yang signifikan antara variabel $\mathrm{x}$ dan variabel y. Berdasarkan tabel 4.11 dapat dilihat bahwa nilai Sig adalah 0,000 sedangkan nilai a adalah 0,1 atau Sig $=0,000<a=0,1$, maka dapat disimpulkan bahwa ada hubungan yang signifikan antara Konsep Gamification terhadap tingkat Employee Engagement.

\section{E. Analisis Regresi Linier Sederhana}

Dari analisis linier sederhana yang dilakukan menunjukkan bahwa hasil uji regresi dapat dilihat dari $\mathrm{R}$ square dimana variabel $\mathrm{X}$ mempengaruhi sebesar 0,384 terhadap variabel Y. Sehingga dapat dikatakan bahwa pengaruh konsep Gamification terhadap tingkat Employee Engagement adalah sebesar $38.4 \%$ sedangkan $61.6 \%$ dipengaruhi oleh faktor lain yang tidak diteliti pada penelitian ini. Interpretasi koefisien korelasi nilai $R$, mendeskripsikan skala interval terhadap tingkat hubungan korelasi. Sehingga dapat disimpulkan bahwa hubungan antara Konsep Gamification terhadap tingkat Employee Engagement rendah dan searah. Untuk standard Error of the Estimate, adalah ukuran kesalahan prediksi, nilai sebesar 4,816. Artinya kesalahan dalam memprediksi pengaruh konsep gamification terhadap tingkat employee engagement sebesar 4,816.

TABEL 1. HASIL ANALISIS KoEFISIEN

\begin{tabular}{|c|c|c|c|c|c|c|}
\hline \multicolumn{7}{|c|}{ Coefficientsa } \\
\hline & \multirow{2}{*}{ Model } & \multicolumn{2}{|c|}{$\begin{array}{l}\text { Unstandardize } \\
\text { d Coefficients }\end{array}$} & $\begin{array}{c}\text { Standardiz } \\
\text { ed } \\
\text { Coefficient } \\
\mathrm{s} \\
\end{array}$ & \multirow{2}{*}{$\mathrm{t}$} & \multirow{2}{*}{$\begin{array}{l}\text { Sig } \\
\cdot\end{array}$} \\
\hline & & B & $\begin{array}{l}\text { Std. } \\
\text { Erro } \\
\text { r }\end{array}$ & Beta & & \\
\hline 1 & (Constant) & $\begin{array}{c}17.52 \\
5\end{array}$ & $\begin{array}{c}3.31 \\
6\end{array}$ & & $\begin{array}{c}5.28 \\
5\end{array}$ & $\begin{array}{c}.00 \\
0\end{array}$ \\
\hline & $\begin{array}{c}\text { Konsep } \\
\text { Gamificati } \\
\text { on }\end{array}$ & .552 & .086 & .606 & $\begin{array}{c}6.41 \\
7\end{array}$ & $\begin{array}{c}.00 \\
0\end{array}$ \\
\hline
\end{tabular}

Sumber: Hasil Pengolahan Data SPSS (2017)

Berdasarkan tabel hasil analisis koefisien regresi, bagian ini menggambarkan persamaan regresi untuk mengetahui angka konstan dan uji hipotesis signifikansi koefisien regresi. Dari tabel di atas, maka didapat dianalisis bahwa persamaan regresi untuk memperkirakan Employee Engagement yang dipengaruhi oleh Konsep Gamification adalah :

$$
\begin{gathered}
Y^{\prime}=a+b X \\
Y^{\prime}=17,525+0,552 X
\end{gathered}
$$

Y merupakan Employee Engagement dan X merupakan Konsep Gamification. 1). Nilai konstanta untuk persamaan regresi sebesar 17,525, artinya jika variabel pelatihan Konsep Gamification (X) nilainya 0, maka nilai variabel Employee Engagement adalah sebesar $17,525 ; 2)$. Nilai b untuk persamaan regresi sebesar 0,552, artinya jika Konsep Gamification mengalami kenaikan satu satuan, maka Employee Engagement akan mengalami peningkatan sebesar 0,552 satuan; 3). Lambang plus (+) berarti bahwa variabel pelatihan Konsep Gamification (X) dan variabel Employee Engagement (Y) memiliki hubungan yang searah. Sehingga apabila variabel Konsep Gamification (X) mengalami kenaikan maka variabel Employee Engagement (Y) juga akan mengalami kenaikan, begitu juga sebaliknya.

Dari hasil pengolahan data di atas, maka didapatkan ringkasan penelitian sebagai berikut. 
TABel 2. Hasil PENGOlahan Data

\begin{tabular}{|c|c|c|c|c|}
\hline $\begin{array}{c}\text { Hubungan } \\
\text { Variabel }\end{array}$ & Korelasi & $\begin{array}{c}\text { Pengaru } \\
\mathrm{h}\end{array}$ & $\begin{array}{c}\text { Persamaa } \\
\mathrm{n} \text { regresi }\end{array}$ & $\begin{array}{l}\text { Pengaruh } \\
\text { yang } \\
\text { diberikan }\end{array}$ \\
\hline $\begin{array}{c}\text { Konsep } \\
\text { Gamificatio } \\
n \\
\downarrow \\
\text { Employee } \\
\text { Engagement }\end{array}$ & $\begin{array}{l}0,384 \\
\text { (Rendah } \\
\text { ) }\end{array}$ & $38,4 \%$ & $\begin{array}{ll}Y^{\prime} & = \\
17,525 & + \\
0,552 X & \end{array}$ & $\begin{array}{l}\text { Signifika } \\
\mathrm{n}\end{array}$ \\
\hline
\end{tabular}

Pada hasil pengaruh koefisien determinasi yang diberikan oleh Konsep Gamification terhadap Employee Engagement dapat dijelaskan pada gambar di bawah ini.

\begin{tabular}{|c|c|c|}
\hline $\begin{array}{c}\text { Konsep } \\
\text { Gamification } \\
\text { (Variabel X) }\end{array}$ & $38,4 \%$ & $\begin{array}{c}\text { Employee } \\
\text { Engagement } \\
\text { (Variabel Y) }\end{array}$ \\
\hline
\end{tabular}

Gambar 1. Pengaruh Pelatihan Building The Team TERHADAP MOTIVASI KERJA

Sumber : Hasil Pengolahan Data Penelitian (2017)

\section{F. Pengujian Hipotesis}

Hipotesis dari penelitian ini adalah sebagai berikut: 1). $\mathrm{H}_{0}$ : Konsep Gamification (X) tidak berpengaruh signifikan terhadap tingkat Employee Engagement (Y) The Park Lane Jakarta; 2). $\mathrm{H}_{\mathrm{a}}$ : Konsep Gamification (X) berpengaruh signifikan terhadap tingkat Employee Engagement (Y) The Park Lane Jakarta.

Ketentuan dalam pembuktian hipotesis dengan menggunakan uji signifikansi korelasi Product Moment menurut Sugiyono (2015: 295) adalah sebagai berikut: 1$) \cdot \mathrm{H}_{0}$ diterima dan $\mathrm{H}_{\mathrm{a}}$ ditolak, apabila $\mathrm{r}$ hitung lebih kecil dari $\mathrm{r}$ tabel ( $\mathrm{r}$ hitung $<\mathrm{r}$ tabel); 2). $\mathrm{H}_{\mathrm{a}}$ diterima dan $\mathrm{H}_{0}$ ditolak, apabila $\mathrm{r}$ hitung lebih besar dari $\mathrm{r}$ table ( $\mathrm{r}$ hitung $>\mathrm{r}$ tabel).

Hasil olahan data SPSS pada Tabel 1 didapatkan $\mathrm{r}$ hitung $(\mathrm{R})=0,606$ Bila sampel (N) adalah 73 sampel dan taraf signifikan adalah $10 \%(0,1)$, maka nilai $\mathrm{r}$ tabel $=0,23$ (berdasarkan tabel lampiran nilai $\mathrm{r}$ Product Moment). Dikarenakan nilai $\mathrm{r}$ hitung (R) lebih besar dari $\mathrm{r}$ tabel $(0,606>0,23)$, maka $\mathrm{H}_{\mathrm{a}}$ diterima dan $\mathrm{H}_{0}$ ditolak. Kesimpulannya yaitu terdapat pengaruh signifikan antara Konsep Gamification Terhadap Tingkat Employee Engagement The Park Lane Jakarta.

\section{KESIMPULAN}

Berdasarkan hasil penelitian "Pengaruh Konsep Gamification Terhadap Tingkat Employee Engagement The Park Lane Jakarta", dapat ditarik beberapa kesimpulan sebagai berikut: 1). Pengaplikasian Konsep
Gamification The Park Lane Jakarta berdasarkan pengolahan statistik deskriptif variabel Konsep Gamification (X) diperoleh data sebagai berikut mean terendah adalah sebesar 3.33 pada pernyataan 4 yaitu "Hukuman yang diterapkan membuat saya termotivasi." Dengan range angka berkisar dari 3 (Netral) sampai 4 (Setuju) mengindikasikan bahwa karyawan bersifat netral mengarah ke setuju terhadap hukuman yang diterapkan membuat mereka termotivasi. Sedangkan untuk mean tertinggi adalah $3.99 \quad$ pada pernyataan nomor 2 yaitu "Saya memahami semua persyaratan untuk mendapatkan learning score" Angka tersebut masih berada di antara angka 3 (Netral) dan 4 (Setuju), sehingga dapat disimpulkan bahwa karyawan setuju bahwa mereka memahami seluruh persyaratan untuk mendapatkan learning score. Dengan mean rata-rata keseluruhan 3.809 mengindikasikan bahwa pengaplikasian konsep gamification di The Park Lane Jakarta adalah Netral kearah Setuju; 2). Tingkat engagement karyawan The Park Lane berdasarkan pengolahan statistik deskriptif variabel Employee Engagement (Y) diperoleh data sebagai berikut mean terendah adalah sebesar 3.68 pada pernyataan 17 yaitu "Adanya tanggapan dari perusahaan untuk setiap aspirasi yang saya utarakan". Hal ini mengindikasikan kurangnya tanggapan perusahaan kepada setiap aspirasi yang diutarakan karyawan walaupun demikian mean tertinggi adalah sebesar 4.16 terdapat pada pernyataan 13 yaitu "Saya selalu melakukan yang terbaik untuk meningkatkan kemampuan dalam pekerjaan". Pernyataan nomor 17 dengan dimensi pengukuran recognition dengan range angka berkisar dari 3 (Netral) sampai 4 (Setuju) mengindikasikan bahwa tanggapan perusahaan terhadap aspirasi karyawan berada pada batasan baik. Dengan dimensi pengukuran motivasi dengan range angka berkisar dari 4 (Setuju) sampai 5 (Sangat Setuju) mengidikasikan bahwa setiap karyawan di The Park Lane Jakarta memiliki motivasi yang tinggi dalam bekerja untuk meningkatkan kemampuan pekerjaan mereka dapat disimpulkan bahwa motivasi karyawan The Park Lane Jakarta cukup baik. Dengan mean rata-rata keseluruhan 3.841 mengindikasikan bahwa employee engagement di The Park Lane Jakarta adalah Netral kearah setuju;' 3). Konsep gamification sendiri memberikan dampak yang signifikan terhadap employee engagement berdasarkan hasil pengolahan data yang dilakukan oleh peneliti, ditemukan adanya pengaruh sebesar $38,4 \%$ terhadap employee engagement. Serta menurut pengujian hipotesis dibuktikan dengan diterimanya $\mathrm{H}_{\mathrm{a}}$ dan ditolaknya $\mathrm{H}_{\mathrm{o}}$ pada uji hipotesis. 
Berdasarkan hasil analisis dan simpulan di atas, maka saran yang dapat diberikan kepada hotel The Park Lane Jakarta adalah: 1). Bagi para peneliti, faktor lain yang dapat mempengaruhi motivasi karyawan adalah $61,6 \%$ yang dapat diteliti lebih lanjut agar hasil penelitian dapat dimanfaatkan di bidang pendidikan maupun pihak hotel; 2). Konsep gamification telah dibuktikan memberikan dampak signifikan terhadap engagement karyawan karena dengan adanya tantangan dan goals yang harus dicapai dengan memperoleh skor. Park Lane mulai memanfaatkan website theparklanejakarta.com untuk menunjang kegiatan learning, seperti training-training yang terdapat di website tersebut. Hal tersebut masih dapat dikembangkan lagi dengan menambahkan menu employees' corner pada website yang memiliki fungsi sebagai ruang untuk karyawan mengakses seluruh kegiatan training, memberikan feedback dan suggestion. Juga dengan menambahkan fitur akun virtual untuk setiap karyawan sebagai akun yang digunakan untuk mengakses employees corner. Dengan demikian segala kegiatan training yang dilaksanakan di website akan mendapat skor yang langsung terakumulasi kedalam akun virtual masing-masing karyawan. Dari hal tersebut pada employees' corner dapat juga di munculkan leaderboard dengan tujuan agar setiap karyawan dengan mudah melihat skor kumulatif setiap karyawan. Peneliti juga menemukan bahwa didapati beberapa karyawan kurang mendapat tanggapan atas aspirasi yang mereka utarakan, hal ini dapat dilihat dari pernyataan dengan dimensi pengukuran recognition mendapatkan nilai mean terendah yaitu 3.68 , sehingga dengan adanya employees' corner dapat meningkatkan interaksi antar karyawan serta akan lebih mudah bagi karyawan menyampaikan aspirasi serta tanggapantanggapan mereka seputar kegiatan training, dengan adanya respon langsung yang diberikan dapat meningkatkan employee engagement. Serta melanjutkan implementasi konsep gamification karena dari penelitian yang dilakukan, ditemukan bahwa Konsep Gamification berpengaruh positif bagi Employee Engagement.

\section{DAFTAR RUJUKAN}

Albrecht, S. L., Bakker, A. B., Gruman, J. A., Macey, W. H., \& Saks, A. M. (2015). Employee engagement, human resource management practices and competitive advantage: An integrated approach. Journal of Organizational Effectiveness:
People and Performance, Vol. 2 Issue: 1, pp.7-35, , 7-35.

Conaway, R., \& Garay, M. C. (2014). Gamification and service marketing. (p.111).

French, R. (2015). Employee Engagement is an individual employee's cognitive, emotional and behavioral state directed toward desired organizational outcomes.

French, Shaunda Marie. (2015). My Confodant, My Coworker: The Interpersonal Relatinship of Work Spouses. Disertasi. The University of Southern Mississippi. Retrieved Novermber 12, 2007 ,

from http://aquila.usm.edu/cgi/viewcontent.cgi?a rticle $=1157 \&$ contex $=$ dissertations

Graha, R. D. (2012). Pengaruh Pelatihan Dan Komunikasi Terhadap Kinerja Karyawan Call Center Di Bandung.

Holmes, J. B., \& Elisabeth R. Gee. (2016). A Framework For Understanding GameBased Teaching and Learning. On the Horizon , 1-16.

Ling Suan Choo, N. M.-O. (2013). Organizational practices and employee engagement: a case of Malaysia electronics manufacturing firms. BUSINESS STRATEGY SERIES , 3-10.

M.Kapp, K., Blair, L., \& Mesch, R. (2014). The Gamification of learning and Instruction Field Book : Ideas into Practice. San Fransisco: Wiley.

M.Kapp, K., Blair, L., \& Mesch, R. (2014). The Gamification of Learning and Instruction Field Book : Ideas Into Practice. In The Gamification of Learning and Instruction Field Book : Ideas Into Practice (p. 100). San Fransisco: Wiley.

M.Kapp, K., Blair, L., \& Mesch, R. (2014). The Gamification of Learning and Instruction Fieldbook : Ideas Into Practice. In The Gamification of Learning and Instruction Fieldbook: Ideas Into Practice (pp. 137-149). San Fransisco: Wiley.

Mangkuprawira. (2014). Manajemen Sumber Daya Manusia Strategik.

Priansa, D.J. (2014). Perencanaan \& Pengembangan SDM. Bandung: Alfabeta

Sakamoto, M., Nakajima, T., \& Alexadrova, T. (2012). Value-based design for gamifying daily activities. Entertainment Computing ICEC , 421-424.

Siregar, S. (2013). Metode Penelitian Kuantitatif. Jakarta.:PT Fajar Interpratama Mandiri

Sugiarto, Hendratono, T., \& Sudibyo, D. (2015). Metodologi Penelitian Hospitaliti 
\& Pariwisata. Tanggerang: Matana Publishing.

Sugiarto, Hendratono, T., \& Sudibyo, D. (2015). Metodologi Penelitian Hospitaliti \& Pariwisata. In Metodologi Penelitian Hospitaliti \& Pariwisata (p. 72). Tanggerang: Matana Publishing.

Sugiarto. (2015). Metodologi Penelitian Hospitaliti \& Pariwisata. Tanggerang: Matana Publishing.
Sugiarto. (2015). Metodologi Penelitian Hospitality. Tanggerang: Matana Publishing.

Sugiyono. (2013). Metode Penelitian Kuantitatif, Kualitatif dan R\&D. Bandung: Alfabeta

Wagner, A. S. (2017). How gamification of an enterprise collaboration system increases knowledge contribution: an affordance approach. Journal of Knowledge Management, Vol. 21 Iss 2. 
